\title{
Sex Determination and Sex Differentiation
}

\author{
G. B. Protyusha*, Amal Steffi D and B. Sivapathasundharam \\ Department of Oral Pathology and Microbiology, Meenakshi Ammal Dental College and Hospital, \\ Meenakshi Academy of Higher Education and Research, Chennai - 600095, \\ Tamil Nadu, India; drprotyusha.oralpathology@madch.edu.in
}

\begin{abstract}
Sex determination is arguably the most defining moment of our lives, the point where we inherit $\mathrm{X}$ or $\mathrm{Y}$ chromosome from our father. This initiates a cascade of events that sets in a train of morphological changes, genetic regulations and molecular mechanisms. Following this, our fate is further sealed during sex differentiation and gonadal development owing to the action of sex-specific gonadal hormones. Therefore, the profoundly divergent journeys of male and female lives are decided just by the toss of a genetic coin. The existence of a third gender is also an undeniable aspect of our society. The understanding of the functioning and genetic regulation of the complex process of sexual determination and differentiation is pivotal in comprehension of the basis of human life. Any deviation from the usual mechanisms in the critical stages of development leads to disorders of sexual differentiation leading to sexual ambiguity among individuals. This review discusses the mechanisms that contribute to female and male sex determination and gonadal development, in an attempt to understand the basics of human sex.
\end{abstract}

Keywords: Eunuchs, Forensics, Human Sex, Sex Determination, Sexual Development, Sex Differentiation, Sex Hormones Article chronicle: Date of Submission: 20.03.2019; Date of Acceptance: 15.08.2019; Date of Publication: 24.04.2020

\section{Introduction}

Most often than not, the commonest question asked following the birth of a child is inevitably "Boy or Girl"? The answer to that question, whether male or female, determines our life from that moment forward and influences almost every aspect of our lives including our being and the way of life. So how deep really are the differences and how exactly do they occur? While these questions seem rather simple, but the fact is that they are extraordinarily complex.

The determination of sex is a fundamental and intricate process that begins very early on in the interior world of foetal gonads. The sexual fate of mammals is determined at the stage of fertilisation, however it is revealed much later during the development of foetus when the gonads differentiate into testis and ovaries after a significant period of sexual ambiguity ${ }^{1}$. Sexual development primarily consists of two processes: Sex determination and sex differentiation. The first process determines whether the bipotential primordia will develop into a testis or an ovary whereas the latter process takes place after sex determination and leads to the actual development of testes or ovaries from an undifferentiated $\operatorname{gonad}^{2}$. Sex determination is described to be a default pathway or as suppression thereof and initiation of the alternate pathway. On the other hand, sex differentiation is the result of the antagonistic relationship among the genes influencing testis or ovary development ${ }^{3,4}$. Thus, the basic role of sex determination and differentiation is to equip the developing organisms with the necessary anatomical and physiological characteristics, required for their survival. Gender, on the other hand is a broad term that encompasses one's personal view on themselves and their self-identification as a man or woman (gender identity), or the society's view on them i.e, masculine or feminine or their sexual orientation. It is an age-old social construction that varies across different cultures ${ }^{5}$. Gender diversity exists in a number of cultures where sex and gender are not mixed or are considered only along 
the binary lines of homosexual or heterosexual while many other cultures lack the flexibility and diversity and any deviation from the "apparent normal" is considered a taboo. A third unspecified gender also largely exists in our community, the eunuchs or the "hijras" as we loosely refer them as. They are considered to be a homogenous clan by the society regardless of their physical or endocrine status. They are mostly born with intersex disorders of sexual differentiation and are considered to have a homosexual identity with a female gender role and female gender identity, male secondary sexual characters, with or without male external genitalia. The eunuchs are thus male to female transsexuals with an abnormal genetic makeup, faulty hormonal imprinting and an altered psychosocial take on gender ${ }^{6}$. Although they are an integral part of our community, the understanding of their physicality, functionality, sexual orientation and genetic regulatory network is rather limited and they continue to barely "survive" as opposed to "live" in our society, which ironically is equally theirs.

Sex determination is extremely important to the forensic experts and especially becomes quite a challenge when only fragments of the body are recovered. Forensic dentists can aid in sex determination and identification of individuals using remains such as teeth and skull. Various features of teeth such as tooth morphology, crown size and root length varies between male and female sex and help in determination of sex. Morphology of the jaws and skull patterns can also be used. Furthermore, newer mechanisms such as DNA analysis using PCR and other molecular mechanisms can be used effectively for sex determination of deceased individuals ${ }^{7}$.

\section{Chromosomal basis of Mammalian Sex Determination}

In humans, sex is determined by the sex chromosomes; $\mathrm{XX}$ in females and $\mathrm{XY}$ in males. Sex development in mammals is determined either by the genetic makeup of an individual or their environment through the influence of nutrients, $\mathrm{pH}$ and temperature during the foetal development ${ }^{2}$. The various stages namely sex determination; gonad differentiation and identity maintenance are considered to be consecutive processes that occur owing to complex interactions between transcription factor interactions and signalling molecules which then direct the development of foetus towards male and female ${ }^{2}$.
In an attempt to understand the mechanism of sex determination, Bridges in 1916 studied the sex chromosomes of fruit fly Drosophila melanogaster and attributed the determining mechanism to the $\mathrm{X}$ :autosome ratio i.e. 2:2 in females (XX) and 1:2 in males $(\mathrm{X}: \mathrm{Y})^{1}$. Later, another researcher named Painter described the $\mathrm{X}$ and $\mathrm{Y}$ chromosomes in humans and believed that they would have a similar mechanism of sex determination as in Drosophila melanogaster. However, this hypothesis was proven wrong after almost 30 years when the first sex chromosome aneuploid mammals were discovered. It was seen that individuals with two $\mathrm{X}$ chromosomes and only one $\mathrm{Y}$ chromosome (XXY) developed testes while individuals with a single $\mathrm{X}$ chromosome and no other second $\mathrm{X}$ or $\mathrm{Y}$ chromosome (XO) developed ovaries. This nullifies the X:Autosome ratio theory in which case, the reverse would have been true $^{8,9}$. Interestingly, an experiment done by Alfred Jost on rabbit foetuses demonstrated that if male (XY) and female (XX) rabbit foetuses were castrated in utero before the differentiation stage, they went on to develop oviduct, uterus and external genitalia of that a female and lacked any male accessory structure. This revealed that the development of femaleness is the "default state" and is independent of the gonadal hormones ${ }^{10}$. This further intrigued the researchers to determine what actually led to the determination of testis/ovary and their association with the presence and absence of the Y chromosome ${ }^{1}$. Subsequently, it was found that the development of testes is associated with a single Y-linked gene locus that encodes for the Testis Determining Factor (TDF). This gene is thus responsible for attributing the fate of a developing gonad into male or female. More specifically, the gene corresponding to the TDF locus on Y chromosome, SRY (Sex-determining Region of the Y chromosome) gene is the male determining gene. It is located on the short arm of Y chromosome (Yp11.2). (Figure 1). The presence of this gene in a developing foetus produces testes and the absence of it, leads to the development of ovaries. This further confirms the pivotal role of Y chromosome in sex determination ${ }^{1}$. The SRY gene produces sex-determining region $\mathrm{Y}$ protein which acts as a transcription factor as it contains a DNA binding domain known as HMG (High-mobility Group) box (Figure 2). This peptide bends the part of the DNA it binds to thereby controlling the activity of certain genes. Furthermore, several testis specific genes also contain SRY-binding sites in their enhancers or promoters; this binding initiates the process 
of developmental pathway into male gonads (testes) by preventing the development of female reproductive structures (uterus and fallopian tubes) ${ }^{11}$. However, frame shift mutations of SRY gene hinders its binding/ bending to the DNA. The homology between $\mathrm{X}$ and $\mathrm{Y}$ chromosome in males occurs in a tiny region called the Pseudoautosomal Region (PAR). It is in this region that that pairing and genetic recombination occurs during meiosis. In certain circumstances, restriction of recombination and gene loss or faulty pairing with adjacent non homologous region may cause an abnormal exchange of Y specific DNA onto the $\mathrm{X}$ chromosome, leading to a phenomenon called sex reversal where the chromosomal sex does not match with the phenotypical sex ${ }^{1}$. Besides the master regulator, SRY gene, several other autosomal genes such as SOX9, DAX1, WT1, WNT4 and FGF9 are also involved in sex determination and sexual development of individuals ${ }^{12}$.

\section{Morphology of the Developing Gonad}

Sex determination can be divided into two stages namely the primary and secondary sex determination. The primary sex determination is entirely determined by chromosomes and is not influenced by the environment. Primary sex determination is the determination of the gonads which starts with the formation of bipotential gonad from the genital ridge. The gonadal rudiments consist of the genital ridge epithelium which appears

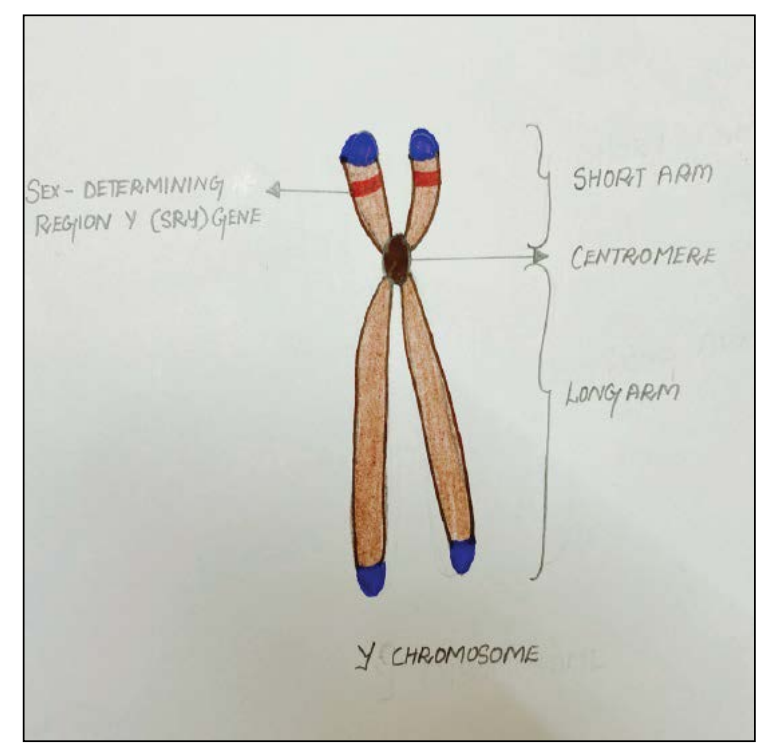

Figure 1: Sex-determining region Y (SRY) gene located on the short arm of $Y$ chromosome.

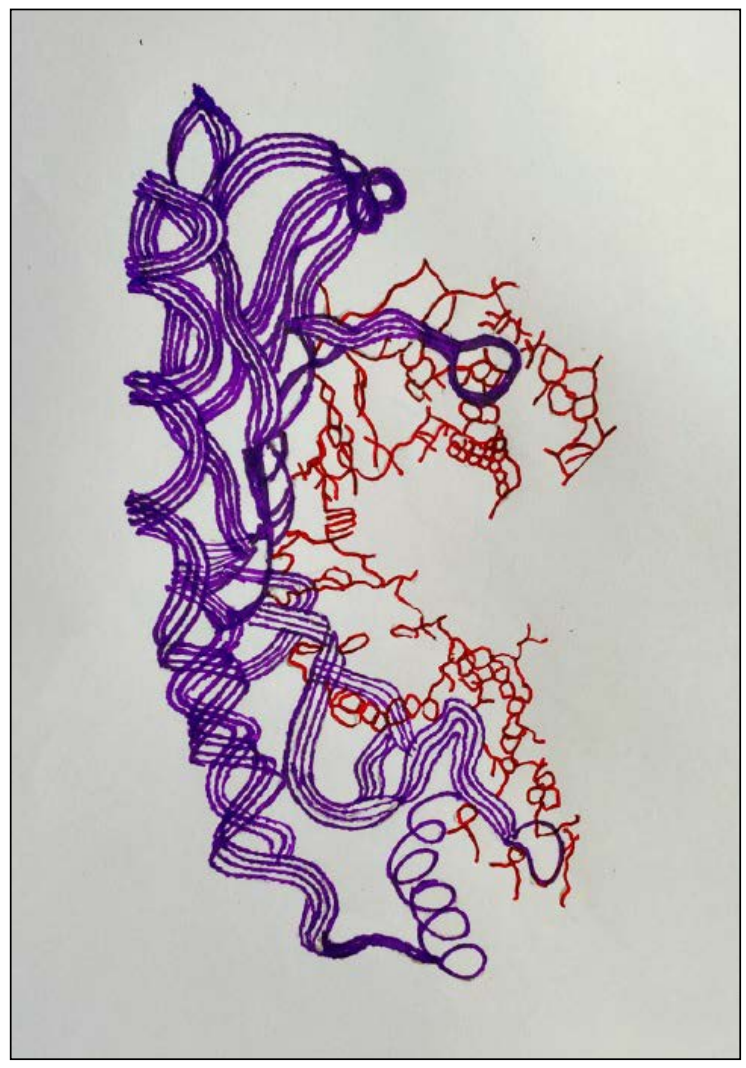

Figure 2: The purple structure represents the HMG box of SRY gene and the red coil represents the DNA which is specifically bound by SRY.

around the fourth week of gestation but remains sexually indifferent till the seventh week $^{11}$. The bipotential gonad is undifferentiated primordia with no male or female characteristics. It however consists of bipotential precursor cells with a capacity to differentiate into one of the two fates: Male or female. Until then, the foetus remains in a state of sexual ambiguity. Precursors for supporting cells and steroid secreting cells are found at this stage which later develops into either testis-specific Sertoli cells or ovary-specific follicle (granulosa) cells ${ }^{13}$. Thus the typical path of early gonadal sex development is the differentiation of bipotential gonad into either males $(46, \mathrm{XY})$ or into females (46, XX). The mammalian primary sex determination is therefore an active, gene instructed process without any "default" state.

Though the determination and differentiation of the gonads occur in the primary sex determination phase, the complete sexual phenotype is determined only in the secondary sex determination stage. This stage involves the development of the sexual phenotypes in response to the hormones secreted by the testes and ovaries. The 
secondary sex determination in both sexes takes place in two temporal phases: during organogenesis within the embryo and during adolescence ${ }^{11}$.

The formation of male phenotype requires the secretion of certain hormones. Two types of cells differentiate in the testes namely Sertoli cells and Leydig cells. The sertoli cells produce the hormone Mullerian Inhibiting Substance (MIS) and the Leydig cells produce testosterone, both of which are needed for normal male foetal development ${ }^{14-17}$. The cells that differentiate inthe ovaries are the follicular cells, steroid producing cells and oocytes $^{11}$.

The MIS produced by the Sertoli cells, causes degeneration of the Mullerian ducts in males. The Wolffian duct, on the other hand, develops in response to the production of testosterone by the Leydig cells and differentiates into the male reproductive structures. In females, Mullerian ducts develop in the absence of MIS and the Wolffian ducts fail to develop in the absence of testosterone production. This leads to the formation of the female reproductive structures ${ }^{11}$. (Figure 3 ).

As mentioned earlier, the removal of bipotential gonad from an embryonic mammal before differentiation leads to the manifestation of female phenotype holds true even for humans born without a functional gonad. Individuals with only one $\mathrm{X}$ chromosome and no second/ $\mathrm{Y}$ chromosome initially develop ovaries which later undergoes atrophy before birth with the germ cells getting destroyed before puberty. However, under the influence of estrogen, initially from the ovaries and later form the mother and the placenta, those individuals are born with a female genital tract ${ }^{18}$.

Like the bipotential gonads, the external genitalia are also initially identical in all foetuses, regardless of the genetic or gonadal sex. Though testosterone is one of the two main masculinising hormones and is responsible for the formation of the male reproductive structures, it does not cause masculinisation of the male urethra, prostate, penis or scrotum. That is brought about by the other masculinising hormone, possibily the more potent one known as Dihydrotestosterone (DHT). It is produced in sufficient amount from gestational weeks 7-8 until birth ${ }^{19}$. If the foetus responds normally to androgens, then the bipotential genitalia develops in a male typical manner. On the contrary, foetal ovaries do not produce androgens that masculinize the external genitalia. Instead it secretes the hormone estrogen in adequate amounts that leads to the differentiation of the uterus, oviducts and cervix.
Finally, in the absence of androgenic effects, the genital tubercule forms a clitoris, the urethral fold develops into the labia minora, the urethral opening is located on the perineum and the genital swellings forms the labia majora. Therefore, in the absence of MIS production, a normal vagina is formed ${ }^{11}$. In the third gender or eunuchs however, the disparity between their phenotypic and genotypic sexual makeup is due to faults in critical stages of sexual determination and differentiation leading to chromosomal imbalance, deletions, translocations or sex reversal. The clinical manifestations of their physical form may be due to reduced production of male sex hormones, abnormal sex organs or improper sexual development in the formative stages ${ }^{20}$.

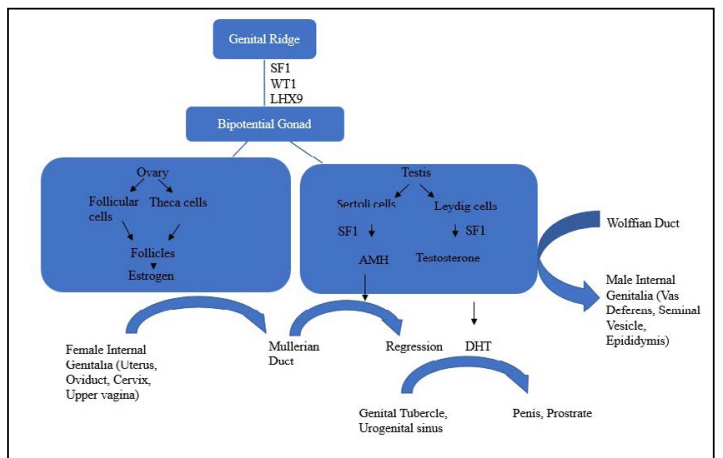

Figure 3: The cascade of events leading to the formation of sexual phenotypes in mammals.

\section{Human Sexual Differentiation}

The sexual differentiation in humans is a series of crucially timed, actively programmed events governed by genetic and hormonal factors that leads to sexual dimorphism. While the sexual fate of the primary gonad is determined solely by the chromosomes, however the decisive factors are the presence or absence of the pivotal hormones such as testosterone and anti Mullerian hormone. The absence of masculinizing genetic factors or hormones at the critical stages of differentiation gives rise to femaleness. Thus human sexual differentiation consists of four basic steps starting with the determination of the genetic sex, differentiation of gonads, differentiation of the internal and external reproductive organs followed by the differentiation of the brain and hypothalamus. It is interesting to note that although the chromosomal, gonadal and hormonal sex is predetermined and governed by the genetic makeup of an individual; the brain and hypothalamus sexual identities are mostly acquired in the postnatal life. In addition, gender and behavioural 
identities are significantly influenced by psychosocial imprinting ${ }^{11,21}$.

The brain is complex organ that is considered to be a sexually differentiated mosaic. Much like the bipotential gonad, even the human brain remains undifferentiated at an early stage of gestation. However, the sex chromosomes in males and females begin to impact the brain in mid gestational stage much before the late gestational hormonal surge in males, influencing the behaviour and brain morphology of individuals ${ }^{21}$. Several studies were conducted to understand the sexual differentiation in brain using rodents in reproductive condition where male rodents showed mounting on females during copulation while females showed lordosis. It was suggested that the behaviour of the males were influenced by testosterone from the testis while the females were influenced by estrodiol and progesterone from the ovaries. However, when the adult male rodents were injected with estrodiol and progesterone, they did notshow significantlordosis and also adult females injected with testosterone did not show mounting on other females as much as males. This proved that males lack certain behavioural capacity inherently and vice versa. Even in studies of reproductive aggression, the expression of aggression in males is expressed more violently over other cage mates than in females who show aggression in different situations such as in protection of their offsprings. ${ }^{21}$ Another hypothesis was suggested in an attempt to understand the brain sexual differentiation where it was stated that brain sexual differentiation runs parallel with genital sexual differentiation. It was believed that the behavioural capacity was also sexually differentiated prenatally by testicular secretion similar to the development of embryonic male genitals by the same hormone ${ }^{22}$. In order to test this hypothesis, studies were conducted where pregnant guinea pigs were injected with testosterone and when they reached the female foetuses, they showed less lordosis and more mounting behaviour than the control group ${ }^{23}$. The hormonal theory of brain sex differentiation also suggested that the male hormone testosterone was responsible for inducing masculinisation by causing permanent changes in the behavioural capacity of the brain. The researchers stated that testosterone acted on the brain prenatally and caused organisational effect which was permanent and differentiating, and later caused activational effect that activated the reproductive behaviour on the changed substrate which was temporary and reversible ${ }^{24}$. The testosterone is thus considered crucial in brain sex differentiation which causes masculinisation in the genitals and is converted to estrogen in the brain to cause masculinisation. However, in humans testosterone can bring about masculinisation both in genitals and in the brain without even converting to estrogen which is not of much significance in humans ${ }^{21}$. It should also be noted that the sexual differentiation in brain is not just governed by genetic or hormonal influence; rather it is greatly influenced by the social and psychological factors.

Human infants are exposed to a highly gendered attitude of the society right from birth. Boys and girls are brought up differently from a very young age, they are expected to behave in certain ways, choose different professions and life paths with considerable differences in physical and emotional stress, diet etc ${ }^{25}$. These social differences undoubtedly influence the sex differences of the brain and may even be the reason of increased prevalence of certain diseases in one of the sexes. It is likely that the occupation more commonly chosen by one sex causes specific kinds of stress in them making them more susceptible to a certain group of diseases ${ }^{26}$. It is thus impossible to decide whether the neural or behavioural phenotype is determined by the biological effect or social/ environmental effect since the two are greatly intertwined. While the male and female brains react differently in regards to reproduction, anxiety, pain, stress, cognition and social behaviour they are also similar in many ways as there are regions in the brain that do not vary at all. Furthermore, specific environments may also nullify the sex-biasing effects of the gonadal hormones in certain regions of brain more than others, thereby reducing the sex differences in a brain region-specific manner ${ }^{26}$.

\section{Conclusion}

The evolution of sex determination in humans and other mammals has seen the proposal of various theories and hypothesis over the years. Insights into genomic and molecular aspects of sex determination have led us to the understanding of the stunningly complex and nuanced mechanisms of the intricate process. It is extremely important to understand the functionality and variability of sex determination of human and the animal kingdom as it is the basis of life for all sexually reproducing species. Though it is now established that SRY gene is imperative in deciding the sex of an individual, various other sex specific genes are also being studied which are yet to be placed 
in a network of regulation and function. In fact, studies need to be conducted to understand the factors involved in regulation of expression of SRY gene, the proteins it binds to and the genes it regulates. Further studies should also be conducted on ovarian development and the genes specific to its determination. Understanding the regulation of sexual determination and differentiation is also a prerequisite to underpin the molecular mechanisms involved in Disorders of Sexual Differentiation (DSD) that leads to various sexual ambiguities. A flaw in any step of sexual development may lead to malformation of the baby's sex organs where individuals can produce both male and female characteristics, referred to as intersexuality ${ }^{27}$. According to the published reports, 1 in 100 live births show some DSDs including genital malformation, gonadal dysgenesis, ambiguous genitalia, sex reversal or syndromes such as Klinefelter syndrome (47, XXY), Swyer syndrome (46, XY) etc. ${ }^{27}$ This may be attributed to various factors such as presence/absence of SRY genes, sex chromosome mosaicism and the intricacies of structural rearrangement. Sex chromosome mosaicism, especially in $45, \mathrm{X}$ cell line has been found to impact the expression of SRY gene, leading to sexual dysgenesis and impairment in early stages of gonadal organogenesis ${ }^{28}$. Studies should be conducted to study the DSDs at molecular levels to develop a thorough understanding of these diseases and devise therapeutic strategies. Furthermore, detailed studies should be conducted to understand the genetic and endocrine functioning of the much neglected third gender which will aid in tailor-made treatment options for them in the form of hormonal therapy and genital sex reassignment surgeries ${ }^{6}$. This will prevent several eunuchs from making detrimental uninformed medical choices and present them a life with high self-esteem and an opportunity to actually "live".

In addition, the dimorphic nature of gonadal development is an extraordinary set up for the demonstration of organogenesis which presents a unique opportunity to study the gene regulatory network of other organs and possibly translate the knowledge into different systems of organogenesis.

Undoubtedly, the knowledge of sex determination and its disorders is also extremely crucial among forensic odontologists, who can be of immense help to the other experts, in identification of sex of deceased individuals even in extreme mishaps involving fire and bacterial decomposition, as dental remains are the most stable tissues in human body ${ }^{7}$.

\section{Conflict of Interest}

The authors declare no conflict of interest.

\section{Ethical Approval}

This article does not contain any studies with human participants or animals performed by any of the authors.

\section{Informed Consent}

Not applicable.

\section{References}

1. Wilhelm D, Palmer S, Koopman P. Sex determination and gonadal development in Mammals. 2021; 1-28.

2. Forconi M, Canapa A, Barucca M, Biscotti MA, Capriglione $\mathrm{T}$, Buonocore $\mathrm{F}$, et al. Characterization of sex determination and sex differentiation genes in Latimeria. PLoS One. 2013; 8(4). PMid: 23634199 PMCid: PMC3636272. https://doi. org/10.1371/journal.pone.0056006

3. Graves JAM, Peichel CL. Figure 1. Phylogeny and sexdetermination systems in vertebrates. 2010.

4. McClelland K, Bowles J, Koopman P. Male sex determination: Insights into molecular mechanisms. Asian J Androl. 2012; 14(1):164-71. PMid:22179516 PMCid: PMC3735148. https://doi.org/10.1038/aja.2011.169

5. Short SE, Yang YC, Jenkins TM. Sex, gender, genetics and health. AJPH 2013;103 S1(Suppl 1):S93-S101. PMid: 23927517 PMCid: PMC3786754. https://doi.org/10.2105/ AJPH.2013.301229

6. Kalra S. The eunuchs of India: An endocrine eye opener. Indian J Endocrinol Metab. 2012; 16(3):377. PMid: 22629502 PMCid: PMC3354843. https://doi.org/10.4103/22308210.95676

7. Ramakrishnan K, Sharma S, Sreeja C, Pratima DB, Aesha I, Vijayabanu B. Sex determination in forensic odontology: A review. J Pharm Bioallied Sci. 2015;7(6):S398-402. PMid: 26538886 PMCid: PMC4606628. https://doi. org/10.4103/0975-7406.163469

8. Jacobs PA. S JA. A case of human intersexuality having a possible XXY sex-determining mechanism. Nature. 1959;183:302-3. PMid: 13632697. https://doi. org/10.1038/183302a0

9. Ford CE, Jones KW, Polani PE, De Almeida JC, Briggs JH. A sex-chromosome anomaly in a case of gonadal dysgenesis (Turner's syndrome). Lancet, 1959; 1:711-713.

10. Jost A, Jost CA. Problems of fetal endocrinology: The gonadal and hypophyseal hormones. RPHR. 1953;8:379-418. 
11. Gilbert SF. Developmental biology. 6th ed. Sunderland (MA): Sinauer Associates; 2000. Chromosomal Sex Determination in Mammals. 2000.

12. She ZY, Yang WX. Molecular mechanisms involved in mammalian primary sex determination. Mol Endocrinol. 2014; 53(1): R21-37. PMid: 24928207. https://doi.org/10.1530/ JME-14-0018

13. Merchant-Larios H, Moreno-Mendoza N, Buehr M. The role of the mesonephros in cell differentiation and morphogenesis of the mouse fetal testis. Int J Dev Biol. 1993; 37(3):407-15.

14. Hacker A, Capel B, Goodfellow P, Lovell-Badge R. Expression of Sry the mouse sex determining gene. Development. 1995;121:1603-14.

15. Und LFZA der maennlichen G, Analdruesen der Saeugethiere. Z Wiss Zool. 1850;2:1-57.

16. Capel B. The battle of the sexes. Mech Dev. 2000; 92:89-103. https://doi.org/10.1016/S0925-4773(99)00327-5

17. Parr BA. Sexually dimorphic development of the mammalian reproductive tract requires Wnt-7a. Nature. 1998; 395:707-10. PMid: 9790192. https://doi.org/10.1038/27221

18. Langman J, Wilson DB. Embryology and congenital malformations of the female genital tract. A. Blaustein (ed.), Pathology of the Female Genital Tract, 2nd Ed. New YorkL Springer-Verlag; 1982. p. 1-20. https://doi.org/10.1007/9781-4757-1767-9_1

19. Siiteri PK, Wilson JD. Testosterone formation and metabolism during male sexual differentiation in the human embryo. JCEM. 1974;38:113-25. PMid: 4809636. https://doi.org/10.1210/jcem-38-1-113

20. Biotechnology C. Clinical Biotechnology and Microbiology Genetics of Eunuchs : A Review. 2018; 1-15.
21. Pfaff DW, Volkow ND. Neuroscience in the 21st century: From basic to clinical, second edition. Neurosci $21^{\text {st }}$ Century From Basic to Clin Second Ed. 2016;1-4155. https://doi.org/10.1007/978-1-4939-3474-4

22. Jost A, Vigier B, Prepin J, Perchelett PJ. Studies on sex differentiation in mammals. Science Direct. 1973; 29:1-41. PMid: 4584366. https://doi.org/10.1016/B978-012-571129-6.50004-X

23. Wallen K. The organizational hypothesis: Reflections on the 50th anniversary of the publication of Phoenix, Goy, Gerall and Y (1959). Hormones and Behavior. 2009;55(5):561-5. PMid: 19446072. https://doi.org/10.1016/j.yhbeh.2009.03.009

24. Phoenix Ch, Goy RW, Gerall AA, Young WC. Organizing action of prenatally administered testosterone propionate on the tissues mediating mating behavior in the female guinea pig. Endocrinology. 1959;65(3):369-82. https://doi. org/10.1210/endo-65-3-369 PMid:14432658

25. Lippa RA. Subdomains of gender-related occupational interests: Do they form a cohesive bipolar M-F dimension? J Pers. 2005;73(3):693-729. PMid: 15854011. https://doi. org/10.1111/j.1467-6494.2005.00326.x

26. Joel D, Berman Z, Tavor I, Wexler N, Gaber O, Stein Y, Shefi N, Pool J, Urchs S, Margulies DS, Liem F, Hanggi J, Jancke L AYS beyond the genitalia: Thuman brain mosaic. PNASUSA 2015; 112:15468-73. PMid:26621705 PMCid:PMC4687544. https://doi.org/10.1073/pnas.1509654112

27. El-Sherbiny M. Disorders of sexual differentiation: I. Genetics and pathology. AJU. 2013;11(1):19-26. PMid: 26579240 PMCid: PMC4442963. https://doi.org/10.1016/j. aju.2012.11.005

28. Roselli CE. Neurobiology of gender identity and sexual orientation. J Neuroendocrinol. 2018;30 (7):e12562.
How to cite this article: Protyusha GB, Steffi DA and Sivapatha sundharam B. Sex Determination and Sex Differentiation. J Forensic Dent Sci 2020;12(1):72-78.

\begin{tabular}{|l|c|}
\hline \multicolumn{2}{|c|}{ Access this article online } \\
\hline \multirow{2}{*}{ Website: } & Quick Response Code \\
\cline { 2 - 2 } www.jfds.org & \\
& \\
&
\end{tabular}

